\title{
In Vitro and In Vivo Antioxidative Activity against Radiation-Induced Damage and the Systematic Chemical Components of Different Extracts of Lagotis brevituba Maxim
}

\author{
Dan Zhang $\mathbb{D},{ }^{1}$ Lihong Tan $\mathbb{D},{ }^{2}$ Ling Yao $\mathbb{D}^{1},{ }^{1}$ Wei Tao $\mathbb{D}^{1},{ }^{1}$ Ruixue Gong $\mathbb{D},{ }^{1}$ \\ Quji LuoRong $\mathbb{1}^{1},{ }^{1}$ and Weiguo Cao $\mathbb{1}^{1}$ \\ ${ }^{1}$ College of Traditional Chinese Medicine, Chongqing Medical University, Chongqing 400016, China \\ ${ }^{2}$ College of Pharmacy, Chongqing Medical and Pharmaceutical College, Chongqing 401331, China \\ Correspondence should be addressed to Weiguo Cao; cwgzd2001@cqmu.edu.cn
}

Received 27 June 2020; Revised 17 November 2020; Accepted 2 December 2020; Published 16 December 2020

Academic Editor: Tadaaki Satou

Copyright ( 2020 Dan Zhang et al. This is an open access article distributed under the Creative Commons Attribution License, which permits unrestricted use, distribution, and reproduction in any medium, provided the original work is properly cited.

\begin{abstract}
Lagotis brevituba Maxim is a perennial species distributed in the highlands of China, which has been used for more than 2000 years as a traditional Tibetan medicinal plant. However, no attention has been paid to the antioxidant activities of Lagotis brevituba Maxim in vitro or in vivo. Thus, this study aimed to evaluate the in vitro and in vivo antioxidant activity of Lagotis brevituba Maxim against radiation-induced damage as well as the systematic chemical components. To explore the relationship between the antioxidant activity and extraction solvent, Lagotis brevituba Maxim was extracted with three different solvents: methanol, water, and acetone. In antioxidant assays in vitro, the water extract had the strongest reducing power, 2,2-azino-bis(3-ethylbenzothiazoline-6-sulfonic acid) diammonium salt (ABTS) radical, and 1,1-diphenyl-2-picrylhydrazyl (DPPH) radical scavenging activity compared with the methanol and acetone extracts. However, the methanol extract was more potent in the $\beta$-carotene/linoleic acid cooxidation assay. In antioxidant assays in vivo, mice that were exposed to $6.0 \mathrm{~Gy}^{60} \mathrm{Co} \gamma$-ray whole-body radiation on day 15 after administration of Lagotis brevituba Maxim decreased their level of malondialdehyde (MDA) in a dose-dependent manner compared with the control group, indicating that Lagotis brevituba Maxim had favorable antioxidant activities in vivo. In addition, a total of 44 compounds were tentatively identified by liquid chromatography electrospray ionization quadrupole time-of-flight mass spectrometry (LC-ESIQTOF-MS/MS), including 19 flavonoids, 14 phenols, 8 phenylethanoid glycosides, 2 iridoid glycosides, and 1 carbohydrate. We obtained 25 compounds from plants in the genus Lagotis for the first time. These results suggested that Lagotis brevituba Maxim had potent antioxidant activity and could be explored as a novel natural antioxidant.
\end{abstract}

\section{Introduction}

Free radicals are metabolic products of the human body, which exist in the human body primarily in the form of superoxide anions, hydroxyl radicals, and hydrogen peroxide radicals. Recently, increasing evidence highlighted that the overproduction of reactive oxygen species (ROS) may contribute to various diseases in the body, such as aging, diabetes, arthritis, atherosclerosis, immune disorders, cancer, inflammation, and heart disease [1-3]. To protect the human body from free radicals, many chemicals are used, such as antioxidants, including butylated hydroxyanisole (BHA), butylated hydroxytoluene (BHT), octylgallate (OG), and propyl gallate (PG) [4]. However, in recent years, many studies have shown that the excessive intake of synthetic antioxidants may be harmful to the health. For example, BHT is considered to be responsible for bladder and thyroid cancer [5]. Therefore, it is essential to develop natural nontoxic antioxidants as alternatives to synthetic ones in the food and pharmaceutical industries.

Lagotis brevituba Maxim (L. brevituba Maxim) is a perennial species distributed in the highlands of China, including Qinghai, Gansu, and Tibet. It has been used for more than 2000 years as a traditional Tibetan medicinal plant. The dried whole plant has been commonly used to treat fever, nephritis, lung disease, and hypertension as well 
as to relieve pain as an ancient Chinese crude drug [6]. Previous studies have shown that L. brevituba Maxim contains phenylethanoid glycosides, phenols, and flavonoids, which are closely related to antioxidant activity $[7,8]$. However, to the best of our knowledge, no attention has been paid to the antioxidant activities of L. brevituba Maxim in vitro or in vivo. In order to utilize this valuable bioresource better, we desired to evaluate the antioxidant activity of L. brevituba Maxim systematically.

In the present study, we extracted L. brevituba Maxim using three different solvents, including methanol, water, and acetone. The in vitro antioxidant activities of the three different extracts were investigated using 2,2-azino-bis(3ethylbenzothiazoline-6-sulfonic acid) diammonium salt (ABTS) radical, 1,1-diphenyl-2-picrylhydrazyl (DPPH), reducing power, and the $\beta$-carotene bleaching test. The potential antioxidant activity in vivo for the water extract was evaluated by measuring the changes in the activities of antioxidant enzymes in mice induced by $\gamma$-ray. The total phenol, flavonoid, and saponin contents of three extracts were also determined. Finally, the chemical compounds in the water extract were analyzed using liquid chromatography electrospray ionization quadrupole time-of-flight mass spectrometry (LC-ESI-QTOF-MS/MS).

\section{Materials and Methods}

2.1. Chemical and Plant Materials. The standards of gallic acid, rutin, and oleanolic acid were purchased from the National Institutes for Food and Drug Control (Beijing, China). The superoxide dismutase (SOD) kit, malondialdehyde (MDA) kit, and glutathione peroxidase (GSH-Px) kit were obtained from Nanjing Jiancheng Bioengineering Institute. All other chemicals and solvents were of analytical grade. The aerial parts of L. brevituba Maxim were collected from Aba County (Sichuan, China) in August 2017, and the samples were identified by Professor Lijuan Mei (Northwest Institute of Plateau Biology (NWIPB), Chinese Academy of Sciences, Xining, China). A voucher specimen (2014090101) was deposited in the herbarium of NWIPB, Xining. The plant materials were shade dried and ground into powder, which was sieved through a $0.8 \mathrm{~mm}$ metal sieve to obtain uniformly sized particles, and the material was stored at $4^{\circ} \mathrm{C}$ until use.

2.2. Extraction Procedure. We extracted $5 \mathrm{~g}$ of powder with methanol, water, and acetone, using an ultrasonic bath for $30 \mathrm{~min}$. Then, the solvents were removed by a rotary evaporator under reduced pressure. Afterward, the obtained residues were dissolved and diluted to $25 \mathrm{~mL}$ with the corresponding solvent. Finally, the extracts were stored at $-20^{\circ} \mathrm{C}$ until analysis.

\subsection{Content Determination}

2.3.1. Determination of the Total Phenol Content. The Folin-Ciocalteu method was used to determine the total phenol contents of the sample extracts [9]. The absorbance was measured at $760 \mathrm{~nm}$ against a blank and using gallic acid as the standard. The total phenol content is expressed in $\mathrm{mg}$ equivalents of gallic acid/g dry weight (mg GAE/g dw.). Measurements were made in triplicate.

2.3.2. Determination of the Total Flavonoid Content. The determination of the total flavonoid contents of L. brevituba Maxim was performed using the spectrophotometric method involving $\mathrm{AlCl}_{3}$ with modifications [10]. The absorbance at $510 \mathrm{~nm}$ was detected using a spectrophotometer, and the total flavonoid content is expressed as mg rutin equivalent (RE) per $1 \mathrm{~g}$ dry weight. All samples were analyzed in triplicate.

2.3.3. Determination of the Total Saponin Content. The total saponin content of the extracts was determined using the vanillin-sulfuric acid method. The extracts were each mixed with $8 \%$ vanillin and $72 \%$ sulfuric acid solution and incubated at $60^{\circ} \mathrm{C}$ for $10 \mathrm{~min}$. Then, the mixtures were cooled in an ice water bath $(15 \mathrm{~min})$, and the absorbances were measured at $538 \mathrm{~nm}$. Oleanolic acid was used as the reference standard, and the content of total saponins is expressed as oleanolic acid equivalents (OAE $\mathrm{g} / \mathrm{mg} \mathrm{dw}$.).

2.3.4. HPLC Analysis. Extracts of L. brevituba Maxim were analyzed for the quantitative determination of echinacea glycosides and mullein glycoside by using a LC-20AD HPLC instrument (including a binary pump, a degasser, a PDA photodiode array detector and an autosampler) (Shimadzu, Kyoto, Japan). A C18 reversed-phase column $(250 \times 4.6 \mathrm{~mm}$, $5 \mu \mathrm{m}$ i.d., SinoChrom, Dalian, China) was used at a flow rate of $1 \mathrm{~mL} / \mathrm{min}$. The injection volume was $10 \mu \mathrm{L}$, and the column oven temperature was set to $35^{\circ} \mathrm{C}$. The mobile phase consisted of (A) $0.2 \%$ aqueous formic acid and (B) acetonitrile solution, and the gradient programme was the following: $0-40 \mathrm{~min}, 13 \%-14 \% \mathrm{~B} ; 40-41 \mathrm{~min}, 14 \%-13 \% \mathrm{~B}$; 41-50 $\mathrm{min}, 13 \% \mathrm{~B}$.

\subsection{Bioactivity Studies}

2.4.1. Antioxidant Capacity Measurements. The analysis was performed using a Shimadzu UV-1750 spectrophotometer at the corresponding wavelength. The measurement was carried out in three stages.

(1) 1,1-Diphenyl-2-picrylhydrazyl (DPPH) Assay. The scavenging ability of the DPPH free radicals of the three extracts was determined using the reported methods $[11,12]$. DPPH ( $0.09 \mathrm{mM}$ of methanol) $(0.8 \mathrm{~mL})$ was added to the extraction solution of different concentrations $(0.2 \mathrm{~mL})$. Afterward, the mixture was stirred and incubated for $60 \mathrm{~min}$ in the dark, and then the absorbance was determined at $517 \mathrm{~nm}$. In the control group, ultra-pure water was used instead of the extract. Vitamin C (VC) and butylated hydroxy toluene (BHT) were used as positive controls. The half maximal inhibitory concentration $\left(\mathrm{IC}_{50}\right)$ was calculated using the linear relationship between the compound concentration 
and the scavenging capacity for DPPH radicals. The percentage DPPH radical scavenging activity was calculated as follows:

percentage of DPPH radical scavenging effect

$$
=\left(\frac{1-\mathrm{OD}_{\text {sample }}}{\mathrm{OD}_{\text {control }}}\right) \times 100 \%,
$$

where $\mathrm{OD}_{\text {sample }}$ is the absorbance of the test sample/reference compound and $\mathrm{OD}_{\text {control }}$ is the absorbance of the control.

(2) 2,2-Azino-bis(3-ethylbenzothiazoline-6-sulfonic Acid) Diammonium Salt (ABTS) Assay. Based on the method of Subhasree et al. [13], the free radical scavenging ability of plant extracts with different concentrations was determined. $\mathrm{VC}$ and BHT were used as positive controls and the extract without ABTS was used as a blank. $\mathrm{ABTS}^{+}$were generated by the reaction of ABTS stock solution with $\mathrm{MnO}_{2}$. Before the assay, the freshly prepared $\mathrm{ABTS}^{+}$solution was diluted with $0.01 \mathrm{M}$ phosphate buffed saline (PBS, $\mathrm{pH} 7.4$ ), and the absorbance was adjusted to $0.70 \pm 0.02$ at $734 \mathrm{~nm}$. We added 50 microliters of each extract at different concentrations to 3 microliters of $\mathrm{ABTS}^{+}$solution, incubated for $6 \mathrm{~min}$ at room temperature under dark conditions, and then the absorbance was measured at $734 \mathrm{~nm}$. The $\mathrm{IC}_{50}$ values of the extracts were also calculated. The calculation results are shown as follows:

ABTS free radical scavenging capacity $\%$

$$
=\left(1-\left(\frac{\mathrm{OD}_{\text {sample }} * \mathrm{OD}_{\text {sample blank }}}{\mathrm{OD}_{\text {control }} * \mathrm{OD}_{\text {control blank }}}\right)\right) \times 100 \% \text {, }
$$

where $\mathrm{OD}$ is the absorbance.

(3) Reducing Power Assay. The reduction power was determined as described by Wang et al. [14], with some modifications. We mixed $1 \mathrm{~mL}$ samples of different concentrations with $2 \mathrm{~mL}$ phosphate buffer ( $\mathrm{pH}$ 6.8) and $2 \mathrm{~mL}$ potassium ferrate $(1 \%)$, incubated at $50^{\circ} \mathrm{C}$ for 20 minutes, and then cooled immediately. Then, $2 \mathrm{~mL}$ trichloroacetic acid was added, shaken vigorously, centrifuged at $3000 \mathrm{rpm}$ for $10 \mathrm{~min}$, and finally $2 \mathrm{~mL}$ upper layer solution was taken. We added $2 \mathrm{~mL}$ ultra-pure water and $1 \mathrm{~mL}$ ferric chloride $(0.1 \%)$, mixed well, and the absorbance at $700 \mathrm{~nm}$ was determined after $10 \mathrm{~min}$. A higher absorbance indicates a stronger potential antioxidant capacity. VC and BHT were used as positive controls.

(4) $\beta$-Carotene/Linoleic Acid Cooxidation Assay. This assay is mainly suitable for the determination of the antioxidant capacity of antioxidants in an emulsified lipid system. The antioxidant activity was determined by the method of Miller et al. [15]. We placed $2 \mathrm{~mL} \beta$-carotene $(0.2 \mathrm{mg} / \mathrm{mL})$ chloroform solution in a pear-shaped bottle, and $20 \mu \mathrm{L}$ linoleic acid was added and mixed with $100 \mathrm{~mL}$ Tavin. Then, the chloroform was removed by rotary evaporation at $40^{\circ} \mathrm{C}$, and $100 \mathrm{~mL}$ distilled water was added to form a uniform emulsion in the blender. A portion of this reaction mixture
$(5 \mathrm{~mL})$ was transferred into test tubes, various concentrations $(0.1 \mathrm{~mL})$ of the extracts were added, and the reaction mixtures were incubated for up to $2 \mathrm{~h}$ in a water bath at $50^{\circ} \mathrm{C}$ in the dark. The same procedure was repeated with BHT (the positive control) and the control in which distilled water was used instead of the extracts. The absorbance values were measured on a spectrophotometer at $470 \mathrm{~nm}$. The rate of the bleaching of the $\beta$-carotene was monitored by measuring the absorbance at $25 \mathrm{~min}$ intervals. The antioxidant activity was calculated according to the following equation:

$$
\text { antioxidant activity } \%=\left(1-\left(\frac{\mathrm{OD}_{\mathrm{so}}-\mathrm{OD}_{\mathrm{st}}}{\mathrm{OD}_{\mathrm{co}}-\mathrm{OD}_{\mathrm{ct}}}\right)\right) \times 100 \% \text {, }
$$

where $\mathrm{OD}_{\mathrm{st}}$ and $\mathrm{OD}_{\mathrm{ct}}$ are the absorbances of the extract and control, respectively, at $120 \mathrm{~min}$, and $\mathrm{OD}_{\text {so }}$ and $\mathrm{OD}_{\text {co }}$ are the absorbances of the extract and control, respectively, at $0 \mathrm{~min}$.

\subsubsection{Antioxidant Determination In Vivo}

(1) Establishment of a Radiation Injury Model. Male and female Kunming mice (14-24 g) of clean grade were provided by the Chongqing Medical University Animal Center. A total of 50 mice were used for these experiments, with 10 mice per group. Mice were randomly assigned to the following treatment groups: normal, control, model, and L. brevituba Maxim: H (high), M (medium), and L (low) dose $(10.0,5.0$, and $2.5 \mathrm{~g}$ body weight $/ \mathrm{mL} /$ day). Distilled water was orally administered to the model and normal groups. All mice except the normal control group were exposed to $6.0 \mathrm{~Gy}^{60} \mathrm{Co} \gamma$-ray whole-body radiation at a dose rate of $1.01 \mathrm{~Gy} / \mathrm{min}$ at a source-to-animal distance (midpoint) of $160 \mathrm{~cm}$ on day 15 after the administration of L. brevituba Maxim water extract. The animals were monitored daily for the development of symptoms of radiation sickness and mortality. All animal experiments proceeded in accordance with the international and national rules regarding animal experimentation and were ratified by the Animal Ethics Committee, Chongqing Medical University, China (no. 2017018).

(2) Determination of SOD, MDA, and GSH-Px. Blood samples were taken from the eyeballs of animals on the seventh day after irradiation. The mice were sacrificed to obtain the brains and livers. Organic tissues were separated and washed with saline. Accurately weighed tissue samples $(1 \mathrm{~g})$ and $9 \mathrm{~mL}$ of precooled saline were mixed with a tissue homogenizer at $10,000 \mathrm{r} / \mathrm{min}$ to prepare a $10 \%$ homogenate. The samples were then centrifuged for $10 \mathrm{~min}$, and the supernatant was removed and stored at $-80^{\circ} \mathrm{C}$. Then, the SOD, MDA, and GSH-Px values from the blood, brains, and livers were measured according to the kit instructions.

\subsection{LC-ESI-QTOF-MS/MS Analysis. LC-ESI-QTOF-MS/MS}

(AB Sciex, Framingham, MA, USA) was used in both the positive and negative ion modes. The optimum ESI operational conditions were as follows: capillary voltage, 
$5.5 \mathrm{kV}$ (ESI+) or $-5.5 \mathrm{kV}$ (ESI-); source temperature, $600^{\circ} \mathrm{C}$; nebulizer gas, $\mathrm{N}_{2}, 55 \mathrm{psi}$; scan range, $50-1000 \mathrm{~m} / \mathrm{z}$. The injection volume was $3 \mu \mathrm{L}$, and the total flow rate was $0.2 \mathrm{~mL} /$ min. We used $1 \%$ formic acid in water (A) and methanol (B) as the gradient mobile phase. The procedure was as follows: $15 \%-20 \%$ B; $20-45 \mathrm{~min}, 20 \%-40 \%$ B; $45-65 \mathrm{~min}, 40 \%-60 \%$ B; $65-75 \mathrm{~min}, 60 \%-80 \% \mathrm{~B}$; and $75-80 \mathrm{~min}, 80 \%-15 \% \mathrm{~B}$.

2.6. Statistical Analysis. All experiments were performed in triplicate, and all data are expressed as the mean \pm standard deviation (SD). One-way analysis of variance (ANOVA) was used for the statistical analysis (SPSS 17.0, SPSS Inc., Chicago, IL, USA). Values of $P<0.05$ were considered statistically significant.

\section{Results and Discussion}

3.1. Content Determination. The solubility of antioxidants in different solvents is different; therefore, choosing the appropriate solvent as the extraction medium is crucial. The contents of total phenols, total flavonoids, and saponins of the L. brevituba Maxim extracts in different solvents are presented in Table 1. The highest contents of phenols (38.59 mg GAE/g), flavonoids (29.29 mg RE/g), and saponins $(13.63 \mathrm{mg} \mathrm{OAE} / \mathrm{g})$ were found in the water extracts, which indicates that there were many polar components in this plant. The solubility of the components varied with their chemical structure and solvent structure. Flavonoids and phenolic components generally have phenolic hydroxyl groups, and so they seldom exist in acetone with a lower polarity [6]. The results showed that water was the most effective solvent for extracting polyphenols from L. brevituba Maxim.

Echinacea glycosides and mullein glycoside are the index components of $L$. brevituba Maxim. In order to control the quality of $L$. brevituba Maxim, the contents were determined. Based on the chromatograms, echinacea glycosides and mullein glycoside in the aqueous extracts were good separated at a retention time of 17.2 and $36.3 \mathrm{~min}$, respectively (Figure 1). According to the HPLC results, the contents of echinacea glycosides and mullein glycoside were $7.34 \mu \mathrm{g} / \mathrm{mg}$ and $9.69 \mu \mathrm{g} / \mathrm{mg}$, respectively.

\subsection{Antioxidant Activity}

3.2.1. DPPH Radical Scavenging Activity. The scavenging DPPH activities of $L$. brevituba Maxim extracts are presented in Figure 2(a). The DPPH inhibition rates increased with the concentration. The antioxidant capacities of the positive controls (BHT and $\mathrm{VC}$ ) were higher, with $\mathrm{IC}_{50}$ values of $0.013 \mathrm{mg} / \mathrm{mL}$ for $\mathrm{VC}$ and $0.014 \mathrm{mg} / \mathrm{mL}$ for BHT, followed by water extract $(0.547 \mathrm{mg} / \mathrm{mL})$, methanol extract $(0.855 \mathrm{mg} / \mathrm{mL})$, and the acetone extract, which showed a substantially weaker activity than the other two extracts. This phenomenon maybe related to the content of phenolic compounds in the extracts. Water extracts have stronger free radical scavenging capacity as they contain more phenolic compounds. This is consistent with the previous literature: there is a highly positive correlation between total phenols and antioxidant activity $[16,17]$.

3.2.2. ABTS Radical Scavenging Activity. The ABTS ${ }^{+}$assay is an excellent tool for determining the antioxidant activity of hydrogen-donating antioxidants and chain-breaking antioxidants. As shown in Figure 1(b), the positive controls BHT and VC had the highest scavenging rates of ABTS free radical, which were close to $95 \%$ when the concentration reached $0.3 \mathrm{mg} / \mathrm{mL}$. Similar to the DPPH scavenging activities, the L. brevituba Maxim extracts were not as potent as the controls, and the water and methanol extracts were noticeably more active than the acetone extract (the $\mathrm{IC}_{50}$ values were $12.754 \mathrm{mg} / \mathrm{mL}$ and $14.792 \mathrm{mg} / \mathrm{mL}$, respectively). Generally, the scavenging activity of ABTS was consistent with the results of the DPPH assay, indicating that the water extract was rich in antioxidant constituents. Comparing the results of DPPH and ABTS, the $\mathrm{IC}_{50}$ value of the former was higher than that of the latter, which indicated that the scavenging capacity of the extract for DPPH radicals was stronger than that of the ABTS radicals.

3.2.3. Ferric Reducing Antioxidant Power. A reducing power assay is an important parameter for compounds to become effective antioxidants and uses a different mechanism to explain antioxidant activity [18]. This method is based on the capacity of antioxidants to reduce $\mathrm{Fe}^{3+} /$ ferricyanide complex to the $\mathrm{Fe}^{2+}$ form [19]. A higher absorbance of the reaction solution indicates a higher $\mathrm{Fe}^{2+}$ content and stronger reduction ability. From the results, it appears that the reduction ability increased with the increase of the concentration, and VC had the strongest reduction ability, followed by the water, methanol, and acetone extracts (Figure 1(c)). The water extract showed the best reducing power compared with the methanol and acetone extracts. We attribute this result to the fact that the water extracts contained more phenolics and flavonoids. In addition, the absorbance of VC at the lowest concentration was approximately 3.5 times that of water extract at the highest concentration. Thus, we propose that the reduction ability of the extract was lower than that of the positive control, but that the extract still provides a moderate reduction ability.

3.2.4. $\beta$-Carotene/Linoleic Acid Cooxidation Activity. The bleaching method of $\beta$-carotene is based on the fact that linoleic acid in emulsion can be oxidized automatically, and the generated free radicals react with $\beta$-carotene to cause the yellow attenuation of $\beta$-carotene. However, in the presence of antioxidants, the bleaching rate of $\beta$-carotene is slowed, and the degree of inhibition or slowing down is related to the antioxidant activity of the substances in the system. The inhibition activities of the samples from the $\beta$-carotene/ linoleic acid cooxidation assay are shown in Figure 1(d). In the control tube without antioxidants, the bleaching rate of $\beta$-carotene was very fast, and the color almost faded within $60 \mathrm{~min}$. However, the absorbance value of the solution increased with L. brevituba Maxim extracts and BHT, but 
TABLE 1: Total phenol, flavonoid, and saponin contents of L. brevituba Maxim extracts.

\begin{tabular}{lccc}
\hline Solvents & Total phenols (GAE mg/g DW) & Total flavonoids $(\mathrm{RE} \mathrm{mg/g} \mathrm{DW)}$ & Total saponins $(\mathrm{OAE}$ mg/g DW) \\
\hline Water & $38.59 \pm 0.70^{\mathrm{c}}$ & $29.29 \pm 0.16^{\mathrm{c}}$ & $13.63 \pm 0.01^{\mathrm{c}}$ \\
Methanol & $28.43 \pm 0.05^{\mathrm{b}}$ & $27.45 \pm 0.82^{\mathrm{b}}$ & $12.75 \pm 0.06^{\mathrm{b}}$ \\
Acetone & $8.18 \pm 0.04^{\mathrm{a}}$ & $6.56 \pm 0.11^{\mathrm{a}}$ & $6.96 \pm 0.03^{\mathrm{a}}$ \\
\hline
\end{tabular}

Values are expressed as mean \pm SEM; different superscript lowercase letters denote statistically significant difference $(P<0.05)$.

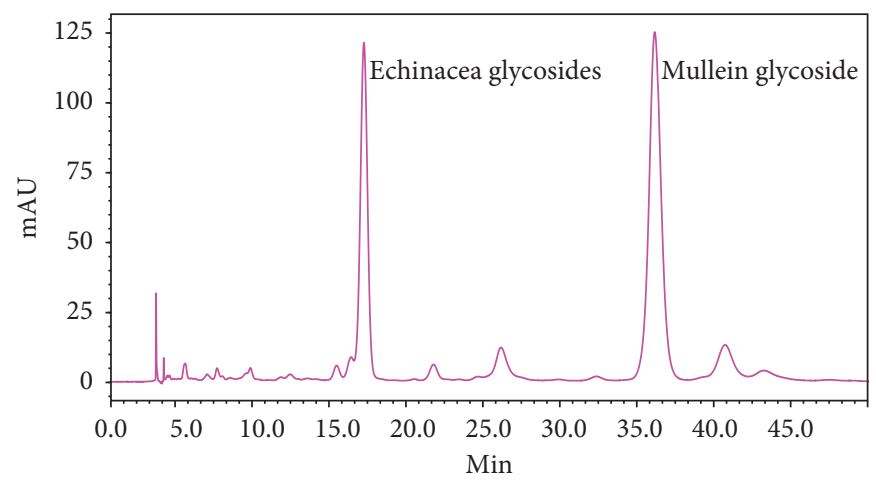

Figure 1: Chromatograms of echinacea glycosides and mullein glycoside in the water extracts.

decreased with the treatment time at $470 \mathrm{~nm}$, and the fading rate of $\beta$-carotene slowed down, which indicated that the extracts and BHT had inhibitory effects on $\beta$-carotene bleaching.

Similar to the results of other antioxidant assays, the acetone extract showed the lowest power; however, there was a difference between the efficacies of the water and methanol extracts, and in this case, the methanol extract was more potent than the water extract. As the reaction curve of the methanol extract was higher than that of the water extract as a whole, the methanol extract always demonstrated a stronger ability to inhibit oxidation than the water extract at each point in time. According to the previous literature, we speculate that this may be due to the fact that many hydrophilic antioxidants cannot be expressed in a lipid emulsion system [20].

3.2.5. Antioxidant Assay In Vivo. MDA is the product of lipid peroxidation induced by oxygen free radicals on unsaturated fatty acids. Its content can reflect the degree of lipid peroxidation in the body and indirectly reflect the degree of damage of oxygen free radicals to cells. SOD and GSH-Px are important antioxidant enzymes in vivo. Their levels indicate the ability of scavenging free radicals [21]. Therefore, to effectively reflect the biological activity of the water extract, we chose these three indicators as biomarkers. The values of SOD, MDA, and GSH-Px in the blood and organic tissue are shown in Table 2. The results indicated that in different tissues, the levels of the three variables were not the same. Except for the MDA content in the blood in high and middle dose groups, the contents of SOD, MDA, and GSH-Px in each tissue and treatment group were significantly different from those in the control group $(P<0.05)$. This may be due to different tissues having different antioxidant abilities; therefore, tissues respond differently to oxidative stress $[22,23]$. With the increasing concentration of $L$. brevituba Maxim water extract, the activities of SOD and GSH-Px increased gradually and then returned to their normal levels, while the amount of MDA decreased to the level of the control group. These results suggest that L. brevituba Maxim can increase the activity of antioxidant enzymes, inhibit lipid peroxidation in vivo, and reduce peroxidation damage in model mice.

3.3. Chemical Composition of L. brevituba Maxim. Putative identification was performed using a detailed study of the fragmentation patterns produced by LC-ESI-QTOFMS/MS in both the positive and negative ion modes with the water extract. Substances in the L. brevituba Maxim extracts were mainly present as glycosides, which were classified as phenols, flavonoids, phenylethanoids, and other glycosides. The loss of 176 daltons is indicative of glucuronide, the loss of 162 daltons is indicative of hexoses (glucose or galactose; the most common sugars found in flavonoids), the loss of 146 daltons is indicative of rhamnose, the loss of 133 daltons is indicative of pentoses (xylose or arabinose; the most common pentoses found in natural products), the loss of 308 daltons is indicative of one molecule of rhamnose plus one of hexose (rutinoside or rhamno-hexoside), and the losses of 90 and 120 daltons are indicative of C-glycoside phenolic compounds $[23,24]$. The compounds in L. brevituba Maxim are discussed below and are summarized in Table 3 and Figure 3.

3.3.1. Phenol. Several phenols in the L. brevituba Maxim extract were tentatively identified by their fragmentation patterns and by comparing their characteristic MS fragmentation data with those reported in the literature. The 


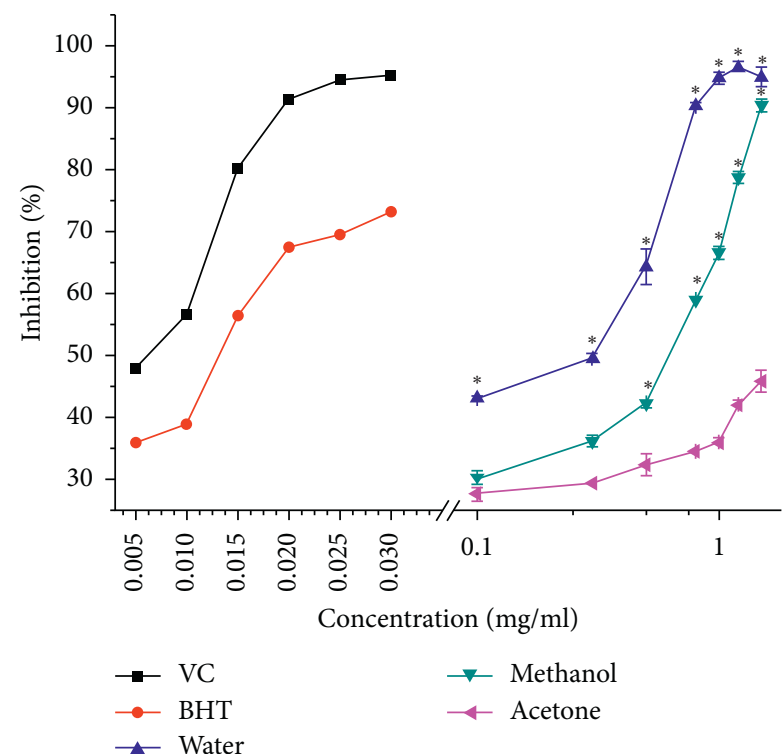

(a)

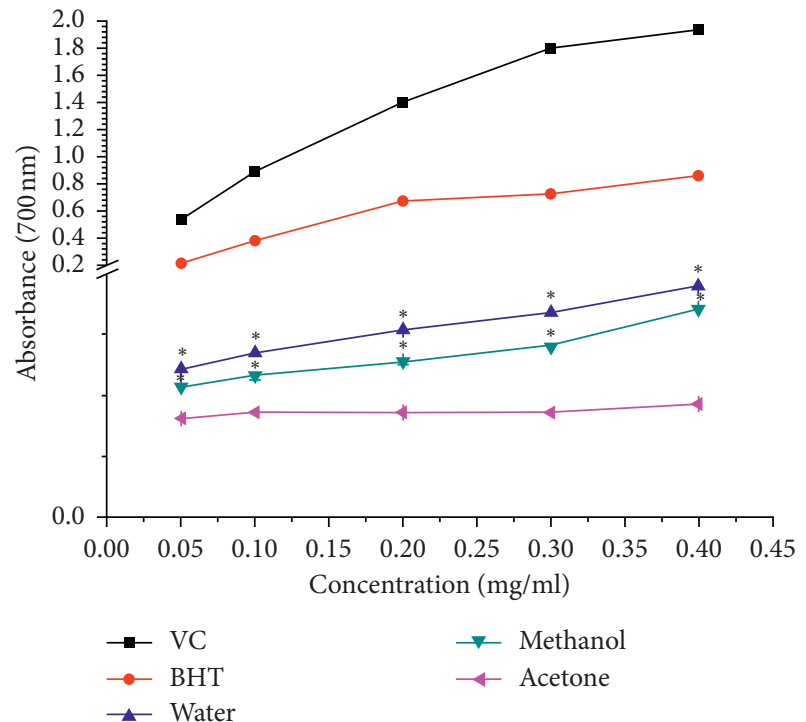

(c)

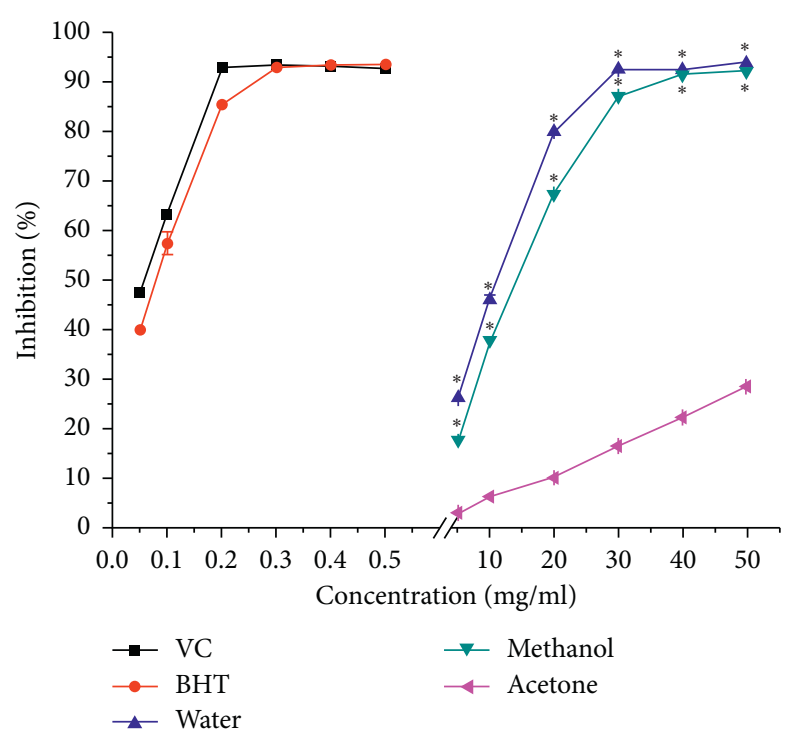

(b)

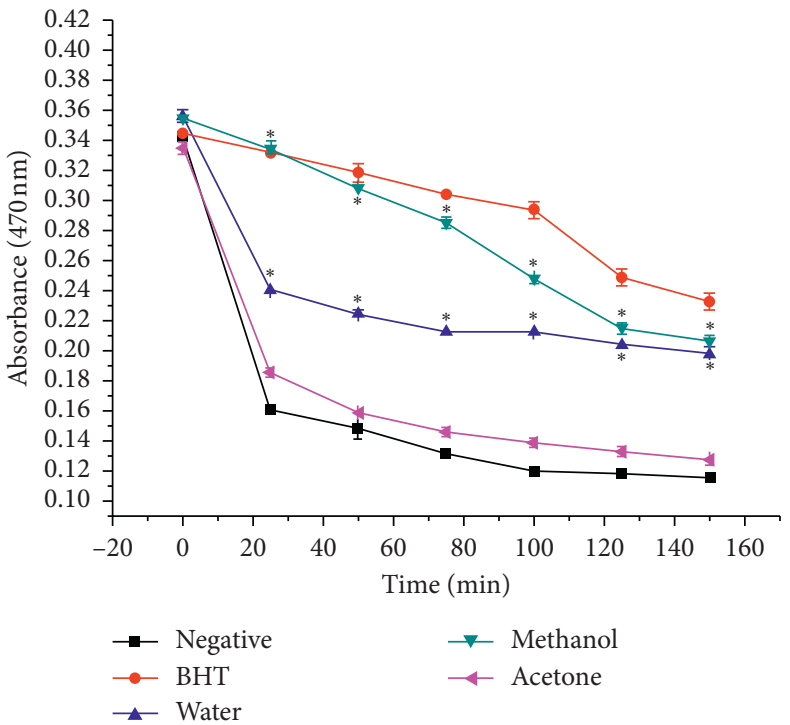

(d)

FIgURE 2: Antioxidant capacity of different solvent extracts from L. brevituba Maxim. (a) DPPH radical scavenging rate. (b) ABTS radical scavenging rate. (c) Ferric reducing antioxidant power. (d) $\beta$-Carotene/linoleic acid cooxidation activity. Values are means \pm S.D. Compared with acetone, ${ }^{*} P<0.05$.

identified compounds can be roughly divided into two main categories, namely, hydroxycinnamic acid derivatives and hydroxybenzoic acid derivatives. The deprotonated molecular ion $[\mathrm{M}-\mathrm{H}]^{-}$at $\mathrm{m} / \mathrm{z} 179$ at $6.57 \mathrm{~min}$ was indicative of caffeic acid (compound 31) [25]. The major fragment ions produced by MS/MS were at $\mathrm{m} / \mathrm{z} 135$, corresponding to the loss of $\mathrm{CO}_{2}$ from the carboxylic acid group with loss of $\mathrm{H}_{2} \mathrm{O}$. Compound 28 and compound 27 were identified as coumaric acid $\left([\mathrm{M}-\mathrm{H}]^{-} \mathrm{m} / \mathrm{z} 163\right)$ and ferulic acid $\left([\mathrm{M}-\mathrm{H}]^{-}\right.$ $\mathrm{m} / \mathrm{z}$ 193), and they produced major fragment ions at $\mathrm{m} / \mathrm{z}$ 119 and 149 , respectively, for the loss of $\mathrm{CO}_{2}$ from their precursor ions [26].The fragmentation patterns of compounds $8\left([\mathrm{M}-\mathrm{H}]^{-} \mathrm{m} / \mathrm{z} 325\right)$ and $10\left([\mathrm{M}-\mathrm{H}]^{-} \mathrm{m} / \mathrm{z} 355\right)$ were similar to those of the aforementioned two acids. The main MS/MS ions at 163 and 193 indicated a loss of hexoside; therefore, those two compounds were identified as coumaric hexoside and ferulic acid hexoside [27]. Compound 7 was identified as rosmarinic acid [28], and the $[\mathrm{M}-\mathrm{H}]^{-}$ion at $\mathrm{m} / \mathrm{z} 359$ was indicative of the two main constituents of rosmarinic acid, namely, caffeic acid at $\mathrm{m} / \mathrm{z}$ 179 and the 2-hydroxy derivative of hydrocaffeic acid at $\mathrm{m} /$ z 197, as illustrated in Figure 4(a).

The other ions at 161 and 135 were the same as those produced by caffeic acid. Compound 42 was identified as cinnamic acid $\left([\mathrm{M}-\mathrm{H}]^{-} \mathrm{m} / \mathrm{z}\right.$ 147), and the ions at $\mathrm{m} / \mathrm{z} 119$ and 101 were consistent with this assignment [29]. The 


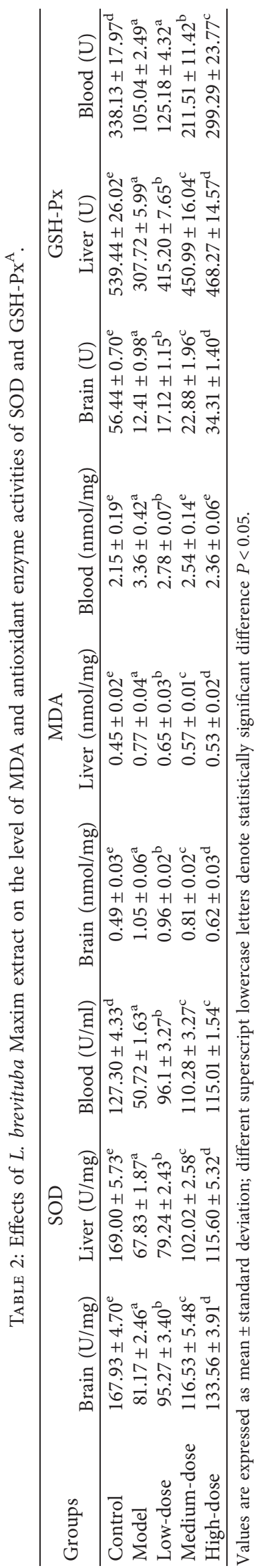


TABLE 3: Identification of the compounds in the extract of L. brevituba Maxim by LC-ESI-QTOF-MS/MS.

\begin{tabular}{|c|c|c|c|c|c|c|c|c|}
\hline $\begin{array}{l}\text { Peak } \\
\text { no. }\end{array}$ & $\begin{array}{c}\mathrm{Rt} \\
(\mathrm{min})\end{array}$ & $\begin{array}{c}\text { Molecular } \\
\text { formula }\end{array}$ & $\begin{array}{c}{[\mathrm{M}+\mathrm{H}]^{+}} \\
(\mathrm{m} / \mathrm{z})\end{array}$ & $\begin{array}{c}{[\mathrm{M}-\mathrm{H}]^{-}} \\
(\mathrm{m} / \mathrm{z})\end{array}$ & $\begin{array}{l}\text { Error } \\
(\mathrm{ppm})\end{array}$ & MS/MS fragments & Proposed compound & Classification \\
\hline 1 & 1.69 & $\mathrm{C}_{12} \mathrm{H}_{22} \mathrm{O}_{11}$ & - & 341.10894 & -0.7 & $\begin{array}{c}179.0560,119.0353 \\
89.0256^{\mathrm{a}}\end{array}$ & Sucrose & Carbohydrate \\
\hline 2 & 1.69 & $\mathrm{C}_{21} \mathrm{H}_{16} \mathrm{O}_{6}$ & 365.10196 & - & 8.6 & $\begin{array}{l}347.0926,275.0721 \\
203.0522,185.0411\end{array}$ & Xanthotoxol hexoside & Phenol \\
\hline 3 & 1.99 & $\mathrm{C}_{16} \mathrm{H}_{22} \mathrm{O}_{10}$ & - & 373.11402 & -1.9 & $211.0950,123.0450^{\mathrm{a}}$ & Geniposidic acid & Iridoid glycoside \\
\hline 4 & 24.59 & $\mathrm{C}_{24} \mathrm{H}_{26} \mathrm{O}_{13}$ & 523.14462 & - & -1.2 & $\begin{array}{c}361.0897,346.0666 \\
272.0664\end{array}$ & Iridin & Flavonoid \\
\hline 5 & 2.34 & $\mathrm{C}_{4} \mathrm{H}_{6} \mathrm{O}_{5}$ & - & 133.01425 & 1 & $\begin{array}{c}115.0031,71.0138 \\
59.0167^{\mathrm{a}}\end{array}$ & Malic acid & Phenol \\
\hline 6 & 23.5 & $\mathrm{C}_{31} \mathrm{H}_{38} \mathrm{O}_{16}$ & - & 665.20871 & 0.5 & $\begin{array}{c}461.1660,161.0240 \\
133.0290^{\mathrm{a}}\end{array}$ & Acetyl acteoside & $\begin{array}{l}\text { Phenylethanoid } \\
\text { glycoside }\end{array}$ \\
\hline 7 & 23.31 & $\mathrm{C}_{18} \mathrm{H}_{16} \mathrm{O}_{8}$ & - & 359.07724 & -1.5 & $\begin{array}{l}197.0465,179.0341 \\
161.0240,135.0442^{\mathrm{a}}\end{array}$ & Rosmarinic acid & Phenol \\
\hline 8 & 3.93 & $\mathrm{C}_{15} \mathrm{H}_{18} \mathrm{O}_{8}$ & - & 325.09289 & -0.9 & $\begin{array}{l}163.0396,119.0503^{\mathrm{a}} \\
191.0556,173.0459\end{array}$ & Coumaric hexoside & Phenol \\
\hline 9 & 4.42 & $\mathrm{C}_{16} \mathrm{H}_{18} \mathrm{O}_{9}$ & - & 353.08781 & -1.9 & $\begin{array}{c}161.0243,85.0292 \\
59.0148^{\mathrm{a}}\end{array}$ & 4-Caffeoylquinic acid & Phenol \\
\hline 10 & 23.26 & $\mathrm{C}_{30} \mathrm{H}_{38} \mathrm{O}_{15}$ & - & 637.21379 & 1 & $\begin{array}{l}461.1652,443.1579 \\
315.1072,193.0498 \\
175.0394,153.0549^{\mathrm{a}}\end{array}$ & Methyl acteoside & $\begin{array}{l}\text { Phenylethanoid } \\
\text { glycoside }\end{array}$ \\
\hline 11 & 21.81 & $\mathrm{C}_{21} \mathrm{H}_{20} \mathrm{O}_{10}$ & 433.11292 & - & -0.9 & $271.0593,153.0171$ & Apigenin hexoside & Flavonoid \\
\hline 12 & 5.92 & $\mathrm{C}_{7} \mathrm{H}_{6} \mathrm{O}_{3}$ & 139.03897 & 137.02442 & 1 & $93.0356,65.0412^{\mathrm{a}}$ & Hydroxybenzoic acid & Phenol \\
\hline 13 & 17.94 & $\mathrm{C}_{21} \mathrm{H}_{18} \mathrm{O}_{12}$ & 463.0871 & 461.07255 & -2.4 & $\begin{array}{l}287.0542,241.0463 \\
153.0175,285.0399^{\mathrm{a}}\end{array}$ & Kaempferol glucuronide & Flavonoid \\
\hline 14 & 9.11 & $\mathrm{C}_{21} \mathrm{H}_{20} \mathrm{O}_{12}$ & 465.10275 & 463.0882 & 0.2 & $\begin{array}{l}303.0498,285.0393 \\
301.0347,300.0264^{\mathrm{a}}\end{array}$ & Quercetin hexoside & Flavonoid \\
\hline 15 & 16.09 & $\mathrm{C}_{16} \mathrm{H}_{12} \mathrm{O}_{7}$ & 317.06558 & - & -0.7 & $302.0413,274.0464$ & Isorhamnetin & Flavonoid \\
\hline 16 & 9.91 & $\mathrm{C}_{35} \mathrm{H}_{46} \mathrm{O}_{21}$ & - & 801.24588 & -0.1 & $\begin{array}{c}639.2160,477.1629 \\
315.1079,161.0248 \\
133.0294^{\mathrm{a}}\end{array}$ & Plantamajoside hexoside & $\begin{array}{l}\text { Phenylethanoid } \\
\text { glycoside }\end{array}$ \\
\hline 17 & 10 & $\mathrm{C}_{27} \mathrm{H}_{30} \mathrm{O}_{16}$ & - & 609.14611 & 0.2 & $\begin{array}{c}447.0840,285.0384 \\
284.0320^{\mathrm{a}}\end{array}$ & Kaempferol dihexoside & Flavonoid \\
\hline 18 & 16.09 & $\mathrm{C}_{22} \mathrm{H}_{22} \mathrm{O}_{12}$ & 479.1184 & - & -0.8 & $\begin{array}{c}317.0648,302.0413 \\
245.0444\end{array}$ & Isorhamnetin hexoside & Flavonoid \\
\hline 19 & 15.96 & $\mathrm{C}_{23} \mathrm{H}_{26} \mathrm{O}_{11}$ & - & 477.14024 & -1 & $\begin{array}{l}315.0501,179.0354 \\
161.0246,133.0259^{\mathrm{a}}\end{array}$ & Desrhamnosyl acteoside & $\begin{array}{c}\text { Phenylethanoid } \\
\text { glycoside }\end{array}$ \\
\hline 20 & 12.83 & $\mathrm{C}_{24} \mathrm{H}_{30} \mathrm{O}_{12}$ & - & 509.16645 & -0.6 & $147.0443^{\mathrm{a}}$ & Globularimin/globularinin & Iridoid glycoside \\
\hline 21 & 12.89 & $\mathrm{C}_{21} \mathrm{H}_{18} \mathrm{O}_{13}$ & - & 477.06746 & -0.2 & $\begin{array}{l}343.0440,301.0339 \\
300.0275,255.0259^{\mathrm{a}}\end{array}$ & Quercetin glucuronide & Flavonoid \\
\hline 22 & 13.51 & $\mathrm{C}_{34} \mathrm{H}_{44} \mathrm{O}_{19}$ & - & 755.2404 & 0.9 & $\begin{array}{c}623.1966,593.2107 \\
575.1989,461.1668 \\
447.1503,315.1076 \\
161.0245,153.0550 \\
133.0291^{\mathrm{a}}\end{array}$ & Lavandulifolioside & $\begin{array}{l}\text { Phenylethanoid } \\
\text { glycoside }\end{array}$ \\
\hline 23 & 15.94 & $\mathrm{C}_{28} \mathrm{H}_{32} \mathrm{O}_{16}$ & 625.17631 & - & -0.9 & $317.0642,302.0415$ & $\begin{array}{l}\text { Isorhamnetinrhamno- } \\
\text { hexoside/Isorhamnetin } \\
\text { rutinoside }\end{array}$ & Flavonoid \\
\hline 24 & 14.86 & $\mathrm{C}_{21} \mathrm{H}_{20} \mathrm{O}_{11}$ & 449.10784 & - & -1 & $\begin{array}{c}287.0543,241.0490 \\
153.0184\end{array}$ & Kaempferol hexoside & Flavonoid \\
\hline 25 & 15.01 & $\mathrm{C}_{27} \mathrm{H}_{30} \mathrm{O}_{15}$ & 595.16575 & 593.15119 & -0.9 & $\begin{array}{l}287.0536,447.0931 \\
285.0389,284.0305^{\mathrm{a}}\end{array}$ & $\begin{array}{c}\text { Kaempferol rhamno- } \\
\text { hexoside/Kaempferol } \\
\text { rutinoside }\end{array}$ & Flavonoid \\
\hline 26 & 15.05 & $\mathrm{C}_{29} \mathrm{H}_{36} \mathrm{O}_{15}$ & - & 623.19814 & 0.1 & $\begin{array}{c}461.1660,161.0248 \\
135.0452^{\mathrm{a}}\end{array}$ & Acteoside/Isoacteoside & $\begin{array}{l}\text { Phenylethanoid } \\
\text { glycoside }\end{array}$ \\
\hline 27 & 13.7 & $\mathrm{C}_{10} \mathrm{H}_{10} \mathrm{O}_{4}$ & - & 193.05063 & 0.8 & $\begin{array}{c}178.0264,149.0616 \\
134.0371^{\mathrm{a}}\end{array}$ & Ferulic acid & Phenol \\
\hline 28 & 11.5 & $\mathrm{C}_{9} \mathrm{H}_{8} \mathrm{O}_{3}$ & - & 163.04007 & 0.3 & $119.0508,93.0359^{\mathrm{a}}$ & Coumaric acid & Phenol \\
\hline
\end{tabular}


TABLE 3: Continued.

\begin{tabular}{|c|c|c|c|c|c|c|c|c|}
\hline $\begin{array}{l}\text { Peak } \\
\text { no. }\end{array}$ & $\begin{array}{c}\mathrm{Rt} \\
(\mathrm{min})\end{array}$ & $\begin{array}{c}\text { Molecular } \\
\text { formula }\end{array}$ & $\begin{array}{c}{[\mathrm{M}+\mathrm{H}]^{+}} \\
(\mathrm{m} / \mathrm{z})\end{array}$ & $\begin{array}{c}{[\mathrm{M}-\mathrm{H}]^{-}} \\
(\mathrm{m} / \mathrm{z})\end{array}$ & $\begin{array}{l}\text { Error } \\
(\mathrm{ppm})\end{array}$ & MS/MS fragments & Proposed compound & Classification \\
\hline 29 & 11.3 & $\mathrm{C}_{29} \mathrm{H}_{36} \mathrm{O}_{16}$ & - & 639.19306 & 0.5 & $\begin{array}{l}477.1610,315.1077 \\
179.0347,161.0242 \\
135.0442,133.0293^{\mathrm{a}}\end{array}$ & Plantamajoside & $\begin{array}{l}\text { Phenylethanoid } \\
\text { glycoside }\end{array}$ \\
\hline 30 & 9.12 & $\mathrm{C}_{15} \mathrm{H}_{10} \mathrm{O}_{7}$ & 303.04993 & 301.03538 & -0.4 & $\begin{array}{c}285.0383, \\
229.0465255 .0319^{\mathrm{a}}\end{array}$ & Quercetin & Flavonoid \\
\hline 31 & 6.57 & $\mathrm{C}_{9} \mathrm{H}_{8} \mathrm{O}_{4}$ & - & 179.03498 & 0.7 & $135.0448,89.0388^{a}$ & Caffeic acid & Phenol \\
\hline 32 & 21.3 & $\mathrm{C}_{27} \mathrm{H}_{30} \mathrm{O}_{14}$ & 579.17083 & - & -1.2 & $271.0593,153.0211$ & $\begin{array}{l}\text { Apigeninrhamno-hexoside/ } \\
\text { Apigenin rutinoside }\end{array}$ & Flavonoid \\
\hline 33 & 5.16 & $\mathrm{C}_{35} \mathrm{H}_{46} \mathrm{O}_{20}$ & - & 785.25097 & 0.8 & $\begin{array}{l}623.2213,179.0357, \\
161.0247,133.0292^{\mathrm{a}}\end{array}$ & Echinacoside & $\begin{array}{l}\text { Phenylethanoid } \\
\text { glycoside }\end{array}$ \\
\hline 34 & 23.18 & $\mathrm{C}_{28} \mathrm{H}_{32} \mathrm{O}_{15}$ & 609.1814 & - & -1.9 & $\begin{array}{l}463.1253,301.0696 \\
286.0457,258.0505, \\
229.0469,153.0168\end{array}$ & $\begin{array}{l}\text { Chrysoeriolrhamnoside } \\
\text { hexoside }\end{array}$ & Flavonoid \\
\hline 35 & 4.62 & $\mathrm{C}_{16} \mathrm{H}_{20} \mathrm{O}_{9}$ & - & 355.10346 & -2.7 & $\begin{array}{l}193.0507,134.0373^{\mathrm{a}} \\
109.0297,108.0218\end{array}$ & Ferulic acid hexoside & Phenol \\
\hline 36 & 3.58 & $\mathrm{C}_{7} \mathrm{H}_{6} \mathrm{O}_{4}$ & - & 153.01933 & 1.5 & $\begin{array}{c}91.0189,81.0358,65.0032 \\
53.0422^{\mathrm{a}}\end{array}$ & Protocatechuic acid & Phenol \\
\hline 37 & 2.52 & $\mathrm{C}_{6} \mathrm{H}_{8} \mathrm{O}_{7}$ & - & 191.01973 & -0.3 & $\begin{array}{c}111.0085,87.0075, \\
59.0149^{\mathrm{a}}\end{array}$ & Citric acid & Phenol \\
\hline 38 & 23.64 & $\mathrm{C}_{22} \mathrm{H}_{22} \mathrm{O}_{11}$ & 463.12349 & - & -0.6 & $\begin{array}{c}301.0705,286.0465 \\
229.0493\end{array}$ & Chrysoeriol hexoside & Flavonoid \\
\hline 39 & 2.22 & $\mathrm{C}_{4} \mathrm{H}_{6} \mathrm{O}_{4}$ & - & 117.01933 & 0.5 & $99.9251,73.0305^{\mathrm{a}}$ & Succinic acid & Phenol \\
\hline 40 & 25.51 & $\mathrm{C}_{21} \mathrm{H}_{18} \mathrm{O}_{11}$ & 447.09219 & - & -1.8 & $\begin{array}{c}271.0591,229.0486 \\
153.0186\end{array}$ & Apigenin glucuronide & Flavonoid \\
\hline 41 & 33.59 & $\mathrm{C}_{15} \mathrm{H}_{10} \mathrm{O}_{6}$ & - & 285.04046 & -2 & $\begin{array}{c}285.0400,151.0034 \\
133.0296^{\mathrm{a}}\end{array}$ & Luteolin & Flavonoid \\
\hline 42 & 33.89 & $\mathrm{C}_{9} \mathrm{H}_{8} \mathrm{O}_{2}$ & - & 147.04515 & 2.4 & $\begin{array}{c}119.0541,103.0557 \\
101.0410,77.0392 \\
61.9906^{\mathrm{a}}\end{array}$ & Cinnamic acid & Phenol \\
\hline 43 & 39.27 & $\mathrm{C}_{15} \mathrm{H}_{10} \mathrm{O}_{5}$ & - & 269.04555 & -3.3 & $\begin{array}{c}117.0343,107.0136 \\
83.0119^{\mathrm{a}}\end{array}$ & Apigenin & Flavonoid \\
\hline 44 & 40.38 & $\mathrm{C}_{16} \mathrm{H}_{12} \mathrm{O}_{6}$ & 301.07066 & 299.05611 & -0.2 & $\begin{array}{c}286.0455,258.0509, \\
229.0498,153.0173, \\
284.0321,256.0362, \\
227.00328^{\mathrm{a}}\end{array}$ & Chrysoeriol & Flavonoid \\
\hline
\end{tabular}

${ }^{a}$ Fragmentation pattern in negative ionization mode.

$[\mathrm{M}-\mathrm{H}]^{-}$ion at $\mathrm{m} / \mathrm{z} 353$ was identified as 4-caffeoylquinic acid [30], which gave MS/MS ions at m/z 191, 173, and 161. The product ion at $\mathrm{m} / \mathrm{z} 191$ was for the quinic acid part, and the ion at $\mathrm{m} / \mathrm{z} 161$ was for the caffeic acid part, which revealed that compound 9 was derived from the condensation of these two constituents. The $[\mathrm{M}-\mathrm{H}]^{-}$signals at $\mathrm{m} / \mathrm{z} 153$ and $\mathrm{m} / \mathrm{z}$ 137 were identified as protocatechuic acid (compound 36) [31] and hydroxybenzoic acid (compound 12) [32], respectively, which are both hydroxybenzoic acid derivatives. Three other reference phenolic acids were also observed and identified in L. brevituba Maxim. The $[\mathrm{M}-\mathrm{H}]^{-}$ion at $\mathrm{m} / \mathrm{z} 117$ gave the fragment ions at $\mathrm{m} / \mathrm{z} 99$ and 73 and was identified as succinic acid (compound 39) [33]. The $[\mathrm{M}-\mathrm{H}]^{-}$ion at $\mathrm{m} / \mathrm{z}$ 133 gave fragment ions at $\mathrm{m} / \mathrm{z} 115,71$, and 59 and was identified as malic acid (compound 5) [25]. The $[\mathrm{M}-\mathrm{H}]^{-}$ion at $\mathrm{m} / \mathrm{z} 191$ gave fragment ions at $\mathrm{m} / \mathrm{z} 111,87$, and 59 and was identified as citric acid (compound 37) [31].

3.3.2. Flavonoids. Flavonoids represent another important group of metabolites that were characterized in this study [34]. The MS/MS spectra of the protonated molecules
$\left([\mathrm{M}+\mathrm{H}]^{+}\right)$generated in the positive ion mode yielded the A and $\mathrm{B}$ series of ions characteristic of C-ring cleavage. Two kinds of flavonoids, namely, flavones and flavonols, were observed and identified in this study. For flavones, chrysoeriol, apigenin, luteolin, iridin, and their derivatives were identified in the MS/MS signals. The compound found at 40.38 min was identified as chrysoeriol (compound 44) [35], and its $[\mathrm{M}+\mathrm{H}]^{+}$ion at $\mathrm{m} / \mathrm{z} 301$ and high intensity fragment ion at $\mathrm{m} / \mathrm{z} 286$ indicated the characteristic neutral loss of $\mathrm{CH}_{3}$. The ion at $\mathrm{m} / \mathrm{z} 153$ is abundant in flavonoid compounds, as observed in chrysoeriol, due to the fragmentation pattern of ${ }^{1,3} \mathrm{~A}^{+}$and ${ }^{1,3} \mathrm{~B}^{+}$, and the details are presented in Figure 4(c).

Two compounds that generated $[\mathrm{M}+\mathrm{H}]^{+}$ions at $\mathrm{m} / \mathrm{z}$ 609 (compound 34) and 463 (compound 38) gave the same ion at $\mathrm{m} / \mathrm{z} 301$ and the same fragmentation pattern as was generated by chrysoeriol. Therefore, they were indicated as chrysoeriol derivatives. For compound 34, the fragment ions at $\mathrm{m} / \mathrm{z} 463[\mathrm{M}+\mathrm{H}-146]^{+}$and $301[\mathrm{M}+\mathrm{H}-146-162]^{+}$ indicated a loss of rhamnoside and a loss of hexoside, respectively; thus, this compound was identified as 


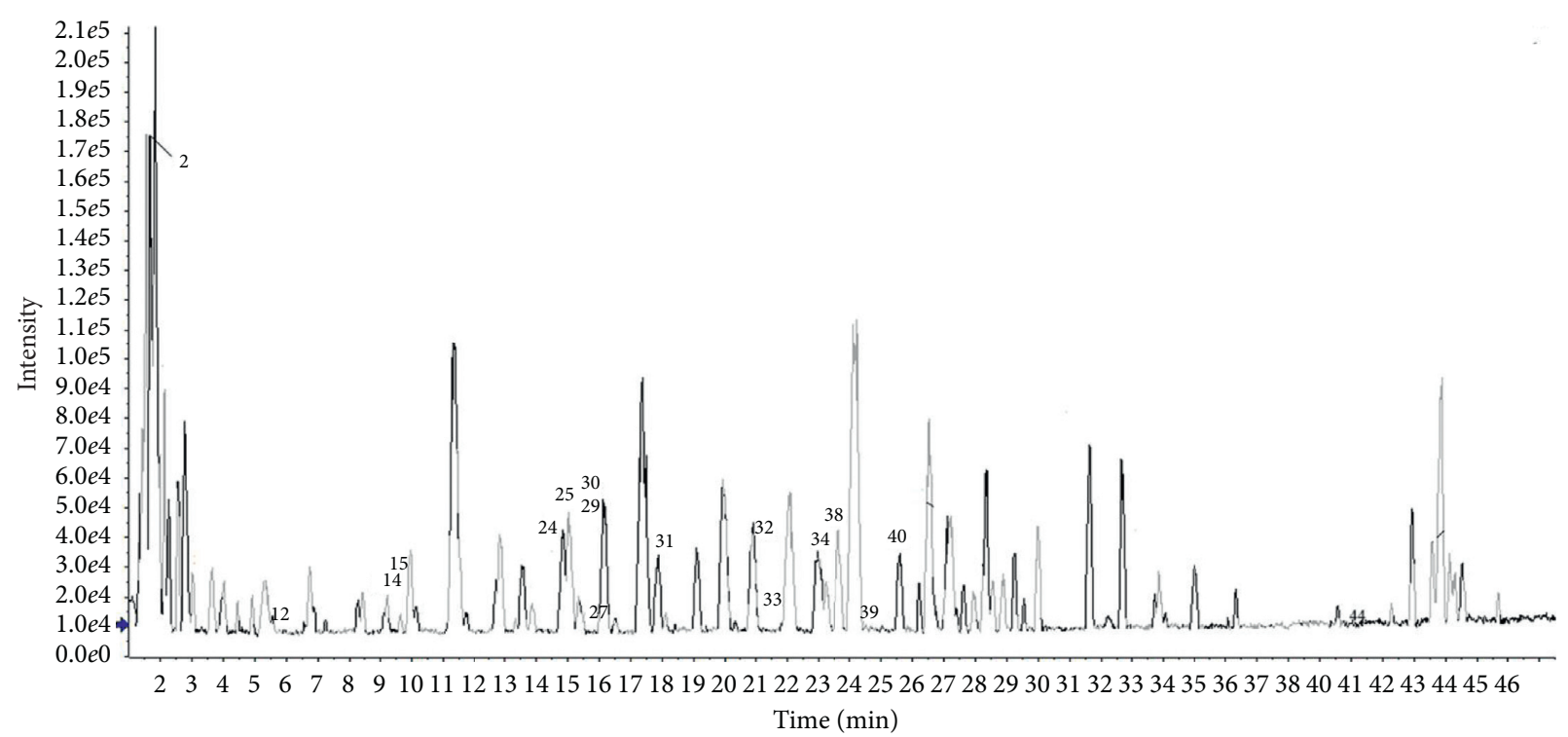

(a)

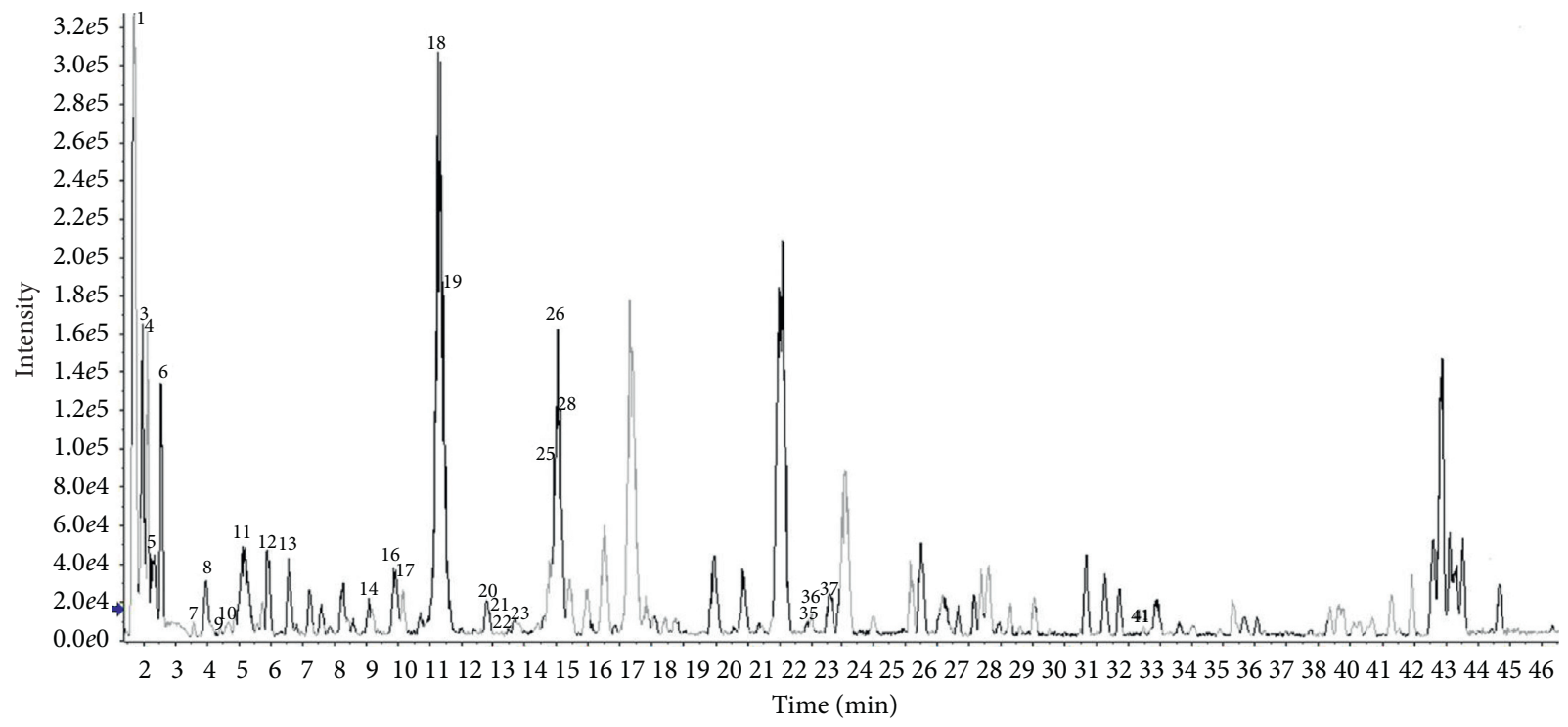

(b)

Figure 3: LC-ESI-QTOF-MS/MS base peak chromatograms (BPC) of L. brevituba Maxim extract. (a) MS in positive ion mode; (b) MS in negative ion mode.

chrysoeriolrhamnoside hexoside, and the accurate positions of the glycosidic bonds are unknown. Similarly, compound 38 was identified as chrysoeriol hexoside. The $[\mathrm{M}-\mathrm{H}]^{-}$ion at $\mathrm{m} / \mathrm{z} 269$ gave fragment ions at $\mathrm{m} / \mathrm{z} 117,107$, and 83 and was identified as apigenin (compound 43) [36]. The other three compounds were classified as apigenin derivatives, namely, apigenin glucuronide (compound 40) with successive fragmentation ions at $\mathrm{m} / \mathrm{z} 447[\mathrm{M}+\mathrm{H}]^{+}$and 271 $[\mathrm{M}+\mathrm{H} \text {-glucuronide }]^{+}$; apigenin hexoside (compound 11) with main fragmentation ions at $\mathrm{m} / \mathrm{z} 433[\mathrm{M}+\mathrm{H}]^{+}$and 271 $[\mathrm{M}+\mathrm{H}-\text { hexoside }]^{-}$; and apigenin rhamno-hexoside or apigenin rutinoside (compound 32) with fragment ions at $\mathrm{m} / \mathrm{z} 579[\mathrm{M}+\mathrm{H}]^{+}$and $271[\mathrm{M}+\mathrm{H}-[$ rhamno-hexoside $] /$ rutinoside $]^{+}$. The compound found in the negative mode at
Rt 33.59 min was identified as luteolin (compound 41) based on its $[\mathrm{M}-\mathrm{H}]^{-}$ion at $\mathrm{m} / \mathrm{z} 285$ and MS/MS ions at 151 and 133 [37]. The $[\mathrm{M}+\mathrm{H}]^{+}$ion at $\mathrm{m} / \mathrm{z} 523$ was identified as iridin (compound 4), and the fragment ions at $\mathrm{m} / \mathrm{z} 361,346$, and 272 were consistent with this assignment [38]. Kaempferol, isorhamnetin, quercetin, and their derivatives were identified from the MS/MS data. The $[\mathrm{M}+\mathrm{H}]^{+}$ion at $\mathrm{m} / \mathrm{z} 317$ gave fragment ions at m/z 302 and 274 and was identified as isorhamnetin (compound 15) [39]. The other two compounds were classified as isorhamnetin derivatives, namely, isorhamnetin hexoside (compound 18) with major fragmentation ions at $\mathrm{m} / \mathrm{z} \quad 479 \quad[\mathrm{M}+\mathrm{H}]^{+}$and 317 $[\mathrm{M}+\mathrm{H}-\text { hexoside }]^{+}$and isorhamnetin rhamno-hexoside or isorhamnetin rutinoside (compound 23) with fragment ions 


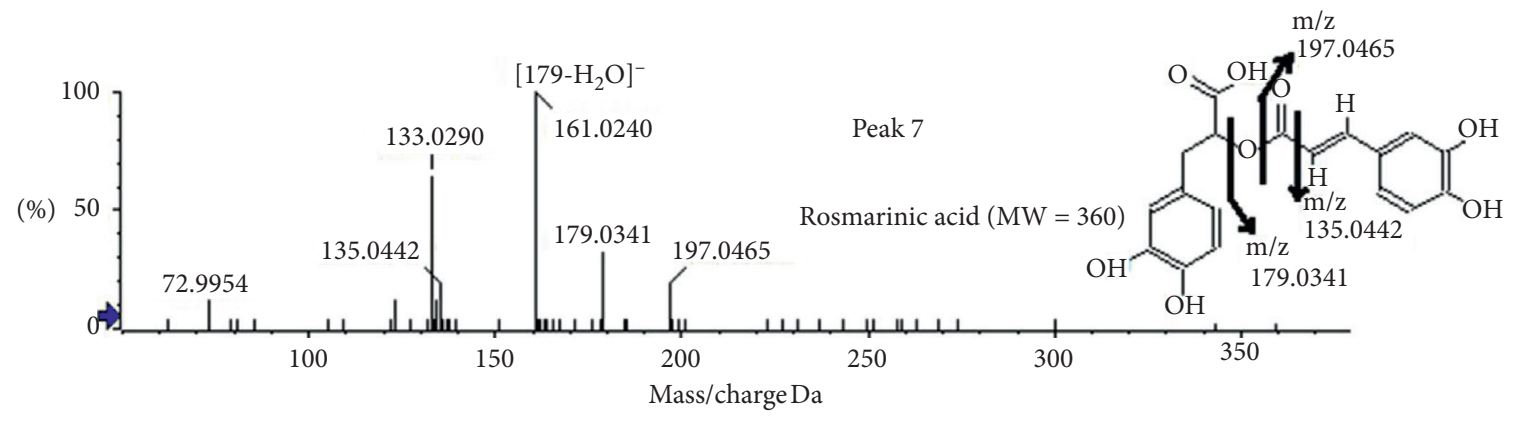

(a)

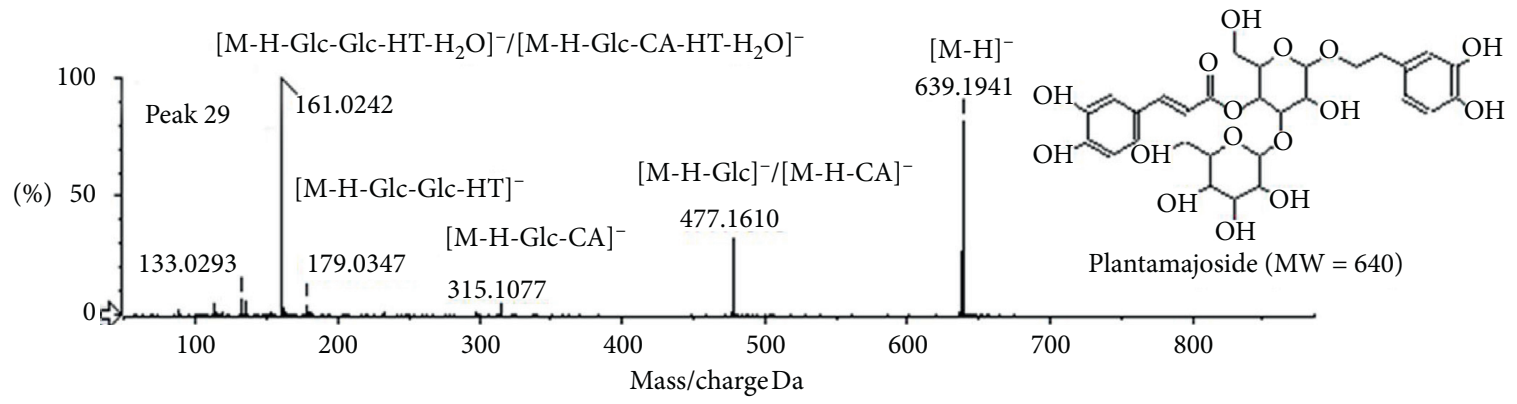

(b)

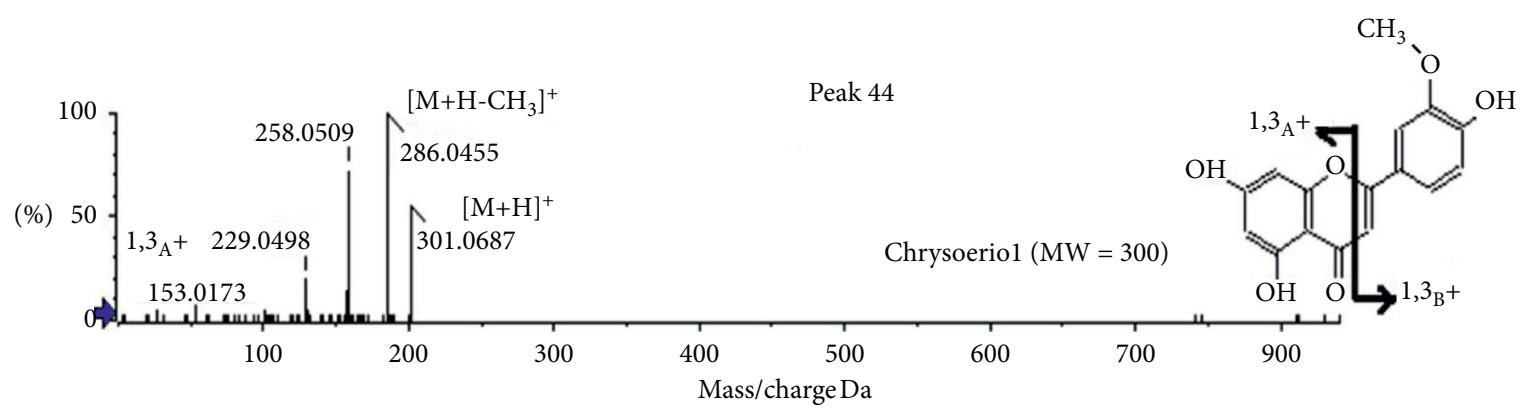

(c)

FIGURE 4: MS/MS spectra of compounds isolated from L. brevituba Maxim extract: (a) peak 7 and (b) peak 29 in negative mode; (c) peak 44 in positive mode.

at $\mathrm{m} / \mathrm{z} 625[\mathrm{M}+\mathrm{H}]^{+}$and $317[\mathrm{M}+\mathrm{H}-[$ rhamno-hexoside $] /$ rutinoside $]^{+}$.

Compound 30 was identified as quercetin because the fragmentation pattern was characteristic of quercetin and was in accordance with previous reports [37]. Compound 21 was identified as quercetin glucuronide because the loss of glucuronide from the $[\mathrm{M}-\mathrm{H}]^{-}$ion at $\mathrm{m} / \mathrm{z} 477$ produced the fragment ion at $\mathrm{m} / \mathrm{z} 301[\mathrm{M}-\mathrm{H}-176]^{-}$. Compound 14 was identified as quercetin hexoside because the loss of hexoside from the $[\mathrm{M}+\mathrm{H}]^{+}$ion at $\mathrm{m} / \mathrm{z} 465$ produced the fragment ion at $\mathrm{m} / \mathrm{z} 303[\mathrm{M}-\mathrm{H}-162]^{-}$. Compounds 17, 24, 25, and 13 were identified as kaempferol glycosides [40] due to their characteristic ions at $\mathrm{m} / \mathrm{z} 287$ in positive mode or $\mathrm{m} / \mathrm{z} 285$ in negative mode and other fragment ions that were consistent with kaempferol. Next, compound 17 was identified as kaempferol hexoside because the $[\mathrm{M}-\mathrm{H}]^{-}$ion at $\mathrm{m} / \mathrm{z} 609$ produced a fragment ion at $\mathrm{m} / \mathrm{z} 447[\mathrm{M}-\mathrm{H}-162]^{-}$, indicating a loss of hexoside, and the subsequent fragment ion at $\mathrm{m} / \mathrm{z} 285$ indicated another loss of hexoside. Compound 24 was identified as kaempferol hexoside because its $[\mathrm{M}+\mathrm{H}]^{+}$ ion at $\mathrm{m} / \mathrm{z} 449$ produced a fragment ion at $\mathrm{m} / \mathrm{z} 287$ $[\mathrm{M}+\mathrm{H}-162]^{+}$, indicating a loss of hexoside. Compound 25 was identified as kaempferol rhamno-hexoside or kaempferol rutinoside because its $[\mathrm{M}+\mathrm{H}]^{+}$ion at $\mathrm{m} / \mathrm{z} 595$ produced a fragment ion at $\mathrm{m} / \mathrm{z} 287[\mathrm{M}+\mathrm{H}-308]^{+}$, indicating a loss of rhamno-hexoside or rutinoside. Compound 13 was identified as kaempferol glucuronide because its $[\mathrm{M}+\mathrm{H}]^{+}$ ion at $\mathrm{m} / \mathrm{z} 463$ produced a fragment ion at $\mathrm{m} / \mathrm{z} 287$ $[\mathrm{M}+\mathrm{H}-176]^{+}$, indicating a loss of glucuronide.

3.3.3. Phenylethanoid Glycoside. In the present work, eight phenylethanoid glycosides were detected in the L. brevituba Maxim extracts. Based on the MS/MS data and literature reports, compound 29 was tentatively identified as plantamajoside [41], and its fragmentation pattern is shown in detail in Figure 4(b). Roughly speaking, this compound could be divided into three fragments, namely, glucose (Glc), caffeic acid (CA), and hydroxytyrosol (HT). The $[\mathrm{M}-\mathrm{H}]^{-}$ ion at $\mathrm{m} / \mathrm{z} 639$ produced a fragment ion at $\mathrm{m} / \mathrm{z} 477$, 
indicating a loss of Glc or CA; the fragment ion at $\mathrm{m} / \mathrm{z}$ 315 indicated the loss of both Glc and CA; the fragment ion at $\mathrm{m} / \mathrm{z} 179$ indicated the loss of two Glc units and a HT moiety; and the fragment ion at $\mathrm{m} / \mathrm{z} 161$ was formed by the loss of Glc, CA, HT, and a molecule of $\mathrm{H}_{2} \mathrm{O}$ or the direct loss of $\mathrm{H}_{2} \mathrm{O}$ from the $\mathrm{m} / \mathrm{z} 179$ ion.

This fragmentation pattern was common in phenylethanoid glycoside and ions such as $\mathrm{m} / \mathrm{z} 315,179,161$, and 133 , and the loss of 162 is typical for this type of substance. Therefore, compound 16 was identified as plantamajoside hexoside; its $[\mathrm{M}-\mathrm{H}]-$ ion at $\mathrm{m} / \mathrm{z} 801$ and the fragment ion at $\mathrm{m} / \mathrm{z} 639$ indicated a loss of hexoside. Compound 26 was identified as acteoside or isoacteoside [42], and compounds 19,10 , and 6 were identified as acteoside derivatives, namely, desrhamnosylacteoside (compound 19), methyl acteoside (compound 10), and acetyl acteoside (compound 6) [43]. In addition, compounds 33 and 22 were determined to be echinacoside [42] and lavandulifolioside [41].

3.3.4. Other Compounds. In addition to the abovementioned compounds identified in this work, we characterized one carbohydrate and two iridoid glycosides. According to their fragmentation profiles, compound 1 was identified as sucrose [44], and compounds 3 and 20, which gave $[\mathrm{M}-\mathrm{H}]^{-}$ions at 373 and 509, respectively, were determined to be geniposidic acid [45] and globularimin or globularinin [32].

\section{Conclusion}

This study comprehensively estimated the antioxidative activity of different extracts and characterized the constituents of $L$. brevituba Maxim extracts. The results indicated that the water extract had the highest contents of phenols, flavonoids, and saponins and the strongest antioxidant capacity in vitro in the DPPH assay, ABTS assay, and reducing power assay. However, the $\beta$-carotene/linoleic acid cooxidation assay showed that the methanol extract was the most effective for the lipophilic system. The water extract of L. brevituba Maxim was able to restore the levels of SOD, MDA, and GSH-Px to normality and protect mice from radiation injury in vivo. In addition, a total of 44 compounds were tentatively identified by LC-ESIQTOF-MS/MS, including 19 flavonoids, 14 phenols, 8 phenylethanoid glycosides, 2 iridoid glycosides, and 1 carbohydrate, and 25 compounds were obtained for the first time from plants in the genus Lagotis. Thus, we recommend further research be conducted to isolate, identify, and characterize the bioactive compounds that are responsible for the activities. The results also suggested that L. brevituba Maxim has considerable antioxidant activities and could be utilized as a new natural antioxidant in food and therapeutics.

\section{Data Availability}

The data used to support the findings of this study are available from the corresponding author upon request.

\section{Conflicts of Interest}

The authors declare that there are no conflicts of interest.

\section{Authors' Contributions}

Dan Zhang, Lihong Tan, and Weiguo Cao conceived and designed the experiments. Dan Zhang and Lihong Tan performed the experiments, analyzed the data, and drafted the manuscript. Ling Yao contributed to the animal experiments. Wei Tao, Ruixue Gong, and Quji LuoRong revised the manuscript. All of the authors read and approved the final manuscript. Dan Zhang and Lihong Tan contributed equally to this work; they are the co-first authors. Weiguo Cao is the corresponding author.

\section{Acknowledgments}

This work was supported by Science and Technology Innovation Project regarding social undertakings and people's livelihood security from the Chongqing Science and Technology Commission (grant no. cstc2018jscx-mszdX0007 and cstc2017shmsA130014) and Chongqing Medical and Pharmaceutical College (no. ygz2018307). The authors wish to express their gratitude to Dr. Yanlei Guo, from the Chongqing Institute of Traditional Chinese Medicine (TCM), China, for his support in the LC-ESI-QTOF-MS/MS analysis.

\section{References}

[1] Y. Chen, B. Huang, J. He, L. Han, Y. Zhan, and Y. Wang, "In vitro and in vivo antioxidant effects of the ethanolic extract of Swertia chirayita," Journal of Ethnopharmacology, vol. 136, no. 2, pp. 309-315, 2011.

[2] B. Halliwell and J. M. C. Gutteridge, "The definition and measurement of antioxidants in biological systems," Free Radical Biology and Medicine, vol. 18, no. 1, pp. 125-126, 1995.

[3] L. E. Rikans and K. R. Hornbrook, "Lipid peroxidation, antioxidant protection and aging," Biochimica et Biophysica Acta (BBA)-Molecular Basis of Disease, vol. 1362, no. 2-3, pp. 116-127, 1997.

[4] M. Anraku, J. M. Gebicki, D. Iohara et al., "Antioxidant activities of chitosans and its derivatives in in vitro and in vivo studies," Carbohydrate Polymers, vol. 199, pp. 141-149, 2018.

[5] P. Kulawik, F. Özogul, R. Glew, and Y. Özogul, "Significance of antioxidants for seafood safety and human health," Journal of Agricultural and Food Chemistry, vol. 61, no. 3, pp. 475-491, 2013.

[6] X. Yuan, H. Wen, Y. Cui et al., "Phenolics from Lagotis brevituba Maxim," Natural Product Research, vol. 31, no. 3, pp. 362-366, 2017.

[7] S. de Marino, C. Festa, F. Zollo et al., "Antioxidant activity of phenolic and phenylethanoid glycosides from Teucrium polium L." Food Chemistry, vol. 133, no. 1, pp. 21-28, 2012.

[8] H. Qu, Y. Zhang, X. Chai, and W. Sun, "Isoforsythiaside, an antioxidant and antibacterial phenylethanoid glycoside isolated from Forsythia suspensa," Bioorganic Chemistry, vol. 40, no. 1, pp. 87-91, 2012.

[9] V. L. Singleton, R. Orthofer, and R. M. Lamuela-Raventós, "Analysis of total phenols and other oxidation substrates and antioxidants by means of folin-ciocalteu reagent," in Oxidants 
and Antioxidants, L. Packer, Ed., vol. 299, pp. 152-178, Academic, San Diego, CA, USA, 1999.

[10] C. Chang, M. Yang, H. Wen et al., "Estimation of total flavonoid content in propolis by two complementary colorimetric methods," Journal of Food and Drug Analysis, vol. 10, no. 3, pp. 178-182, 2002.

[11] W. Brand-Williams, M. E. Cuvelier, and C. Berset, "Use of a free radical method to evaluate antioxidant activity," $L W T$ Food Science and Technology, vol. 28, no. 1, pp. 25-30, 1995.

[12] J. Guo, D. Zhang, C. Yu et al., "Phytochemical analysis, antioxidant and analgesic activities of incarvillea compacta Maxim from the Tibetan plateau," Molecules, vol. 24, no. 9, p. 1692, 2019.

[13] B. Subhasree, R. Baskar, R. Laxmi Keerthana, R. Lijina Susan, and P. Rajasekaran, "Evaluation of antioxidant potential in selected green leafy vegetables," Food Chemistry, vol. 115, no. 4, pp. 1213-1220, 2009.

[14] X. Wang, Q. Wu, Y. Wu, G. Chen, W. Yue, and Q. Liang, "Response surface optimized ultrasonic-assisted extraction of flavonoids from Sparganii rhizoma and evaluation of their in vitro antioxidant activities," Molecules, vol. 17, no. 6, pp. 6769-6783, 2012.

[15] H. E. Miller, "A simplified method for the evaluation of antioxidants," Journal of the American Oil Chemists Society, vol. 48 , no. 2, p. 91, 1971.

[16] K. Wolfe, X. Wu, and R. H. Liu, "Antioxidant activity of apple peels," Journal of Agricultural and Food Chemistry, vol. 51, no. 3, pp. 609-614, 2003.

[17] G. Zengin, M. Locatelli, A. Stefanucci et al., "Chemical characterization, antioxidant properties, anti-inflammatory activity, and enzyme inhibition of Ipomoea batatas L. leaf extracts," International Journal of Food Properties, pp. 1-13, 2017.

[18] E. M. Coelho, M. E. A. O. de Souza, L. C. Corrêa et al., "Bioactive compounds and antioxidant activity of mango peel liqueurs (Mangifera indica L.) produced by different methods of maceration," Antioxidants, vol. 8, no. 4, 2019.

[19] O. Firuzi, A. Lacanna, R. Petrucci et al., "Evaluation of the antioxidant activity of flavonoids by "ferric reducing antioxidant power" assay and cyclic voltammetry," Biochimica et biophysica acta, vol. 1721, no. 1-3, pp. 174-184, 2005.

[20] P. Maisuthisakul, R. Pongsawatmanit, and M. H. Gordon, "Antioxidant properties of teaw (cratoxylum formosumdyer) extract in soybean oil and emulsions," Journal of Agricultural and Food Chemistry, vol. 54, no. 7, pp. 2719-2725, 2006.

[21] E. B. M. I. Peixoto, B. S. Pessoa, S. K. Biswas, and J. B. Lopes de Faria, "Antioxidant SOD mimetic prevents NADPH oxidaseinduced oxidative stress and renal damage in the early stage of experimental diabetes and hypertension," American Journal of Nephrology, vol. 29, no. 4, pp. 309-318, 2009.

[22] I. Ahmad, T. Hamid, M. Fatima et al., "Induction of hepatic antioxidants in freshwater catfish (Channa punctatus Bloch) is a biomarker of paper mill effluent exposure," Biochimica et Biophysica Acta, vol. 1523, no. 1, pp. 37-48, 2000.

[23] M. Simirgiotis, G. Schmeda-Hirschmann, J. Bórquez, and E. Kennelly, "The passiflora tripartita (banana passion) fruit: a source of bioactive flavonoid C-glycosides isolated by HSCCC and characterized by HPLC-DAD-ESI/MS/MS," Molecules, vol. 18, no. 2, pp. 1672-1692, 2013.

[24] M. J. Simirgiotis, C. Theoduloz, P. D. S. Caligari, and G. Schmeda-Hirschmann, "Comparison of phenolic composition and antioxidant properties of two native Chilean and one domestic strawberry genotypes," Food Chemistry, vol. 113, no. 2, pp. 377-385, 2009.
[25] A. Al-Rawahi, G. Edwards, M. Al-Sibani et al., "Phenolic constituents of pomegranate peels (Punica granatum L.) cultivated in Oman," European Journal of Medicinal Plants, vol. 4, no. 3, p. 315, 2014.

[26] A. Vallverdú-Queralt, N. Boix, E. Piqué et al., "Identification of phenolic compounds in red wine extract samples and zebrafish embryos by HPLC-ESI-LTQ-Orbitrap-MS," Food Chemistry, vol. 181, pp. 146-151, 2015.

[27] A. M. Gómez-Caravaca, A. López-Cobo, V. Verardo et al., "HPLC-DAD-q-TOF-MS as a powerful platform for the determination of phenolic and other polar compounds in the edible part of mango and its by-products (peel, seed, and seed husk)," Electrophoresis, vol. 37, no. 7-8, pp. 1072-1084, 2016.

[28] M. B. Hossain, D. K. Rai, N. P. Brunton, A. B. Martin-Diana, and C. Barry-Ryan, "Characterization of phenolic composition in Lamiaceae spices by LC-ESI-MS/MS," Journal of Agricultural and Food Chemistry, vol. 58, no. 19, pp. 1057610581, 2010.

[29] J. Gruz, O. Novák, and M. Strnad, "Rapid analysis of phenolic acids in beverages by UPLC-MS/MS," Food Chemistry, vol. 111, no. 3, pp. 789-794, 2008.

[30] M. Krizman, D. Baricevic, and M. Prosek, "Determination of phenolic compounds in fennel by HPLC and HPLC-MS using a monolithic reversed-phase column," Journal of Pharmaceutical and Biomedical Analysis, vol. 43, no. 2, pp. 481-485, 2007.

[31] J. T. Pierson, G. R. Monteith, S. J. Roberts-Thomson, R. G. Dietzgen, M. J. Gidley, and P. N. Shaw, "Phytochemical extraction, characterisation and comparative distribution across four mango (Mangifera indica L.) fruit varieties," Food Chemistry, vol. 149, pp. 253-263, 2014.

[32] N. Amessis-Ouchemoukh, I. M. Abu-Reidah, R. QuirantesPiné et al., "Tentative characterisation of iridoids, phenylethanoid glycosides and flavonoid derivatives from Globularia alypum L. (Globulariaceae) leaves by LC-ESI-QTOF-MS," Phytochemical Analysis, vol. 25, no. 5, pp. 389-398, 2014.

[33] D. Bylund, S. H. Norström, S. A. Essén et al., "Analysis of low molecular mass organic acids in natural waters by ion exclusion chromatography tandem mass spectrometry," Journal of Chromatography A, vol. 1176, no. 1-2, pp. 89-93, 2007.

[34] A. Mollica, G. Zengin, M. Locatelli et al., "Anti-diabetic and anti-hyperlipidemic properties of Capparis spinosa L.: in vivo and in vitro evaluation of its nutraceutical potential," Journal of Functional Foods, vol. 35, pp. 32-42, 2017.

[35] J. L. Wolfender, P. Waridel, K. Ndjoko, K. R. Hobby, H. J. Major, and K. Hostettmann, "Evaluation of Q-TOF-MS/ MS and multiple stage IT-MSn for the dereplication of flavonoids and related compounds in crude plant extracts," Analysis, vol. 28, no. 10, pp. 895-906, 2000.

[36] E. Hvattum, "Determination of phenolic compounds in rose hip (Rosa canina) using liquid chromatography coupled to electrospray ionisation tandem mass spectrometry and diodearray detection," Rapid Communications in Mass Spectrometry, vol. 16, no. 7, pp. 655-662, 2002.

[37] Z. H. Li, H. Guo, W. B. Xu et al., "Rapid identification of flavonoid constituents directly from PTP1B inhibitive extract of raspberry (Rubus idaeus L.) leaves by HPLC-ESI-QTOFMS-MS," Journal of Chromatographic Science, vol. 54, no. 5, pp. 805-810, 2016.

[38] W. Kukula-Koch, E. Sieniawska, J. Widelski et al., "Major secondary metabolites of Iris spp," Phytochemistry Reviews, vol. 14, no. 1, pp. 51-80, 2015.

[39] G. Enkhtaivan, K. M. Maria John, M. Pandurangan, J. H. Hur, A. S. Leutou, and D. H. Kim, "Extreme effects of Seabuckthorn 
extracts on influenza viruses and human cancer cells and correlation between flavonol glycosides and biological activities of extracts," Saudi Journal of Biological Sciences, vol. 24, no. 7, pp. 1646-1656, 2017.

[40] M. Carmona, A. M. Sánchez, F. Ferreres, A. Zalacain, F. Tomás-Barberán, and G. L. Alonso, "Identification of the flavonoid fraction in saffron spice by LC/DAD/MS/MS: comparative study of samples from different geographical origins," Food Chemistry, vol. 100, no. 2, pp. 445-450, 2007.

[41] S. Gonda, A. Kiss-Szikszai, Z. Szücs, C. Máthé, and G. Vasas, "Effects of $\mathrm{N}$ source concentration and $\mathrm{NH}^{4+} / \mathrm{NO}^{3-}$ ratio on phenylethanoid glycoside pattern in tissue cultures of Plantago lanceolata L.: a metabolomics driven full-factorial experiment with LC-ESI-MS3," Phytochemistry, vol. 106, pp. 44-54, 2014.

[42] Y. Shi, C. Wu, Y. Chen, W. Liu, F. Feng, and N. Xie, "Comparative analysis of three Callicarpa herbs using high performance liquid chromatography with diode array detector and electrospray ionization-trap mass spectrometry method," Journal of Pharmaceutical and Biomedical Analysis, vol. 75, pp. 239-247, 2013.

[43] W. L. Li, X. M. Sun, H. Song, J. X. Ding, J. Bai, and Q. Chen, "HPLC/Q-TOF-MS-based identification of absorbed constituents and their metabolites in rat serum and urine after oral administration of Cistanche deserticola extract," Journal of Food Science, vol. 80, no. 9, pp. H2079-H2087, 2015.

[44] C. Xiao, M. Wu, Y. Chen, Y. Zhang, X. Zhao, and X. Zheng, "Revealing metabolomic variations in Cortex Moutan from different root parts using HPLC-MS method," Phytochemical Analysis, vol. 26, no. 1, pp. 86-93, 2015.

[45] H. Liu, J. Su, X. Liang et al., "Identification and determination of the major constituents in traditional Chinese medicine Longdan Xiegan Pill by HPLC-DAD-ESI-MS," Journal of Pharmaceutical Analysis, vol. 1, no. 1, pp. 1-7, 2011. 